\title{
Impact of hypochloremia in resected colorectal cancer patients
}

\author{
Mai Tsutsui, Seiichiro Yamamoto \\ Department of Surgery, Hiratsuka City Hospital, Kanagawa, 254-0065, Japan \\ Correspondence to: Seiichiro Yamamoto, MD, PhD. Department of Surgery, Hiratsuka City Hospital, 1-19-1, Minamihara, Hiratsuka, Kanagawa, 254- \\ 0065, Japan. Email: miyamamo@jcom.home.ne.jp. \\ Comment on: Li Q, Dai, W, Jia H, et al. Prognostic Impact of Hypochloremia in Patients With Stage I to III Colorectal Cancer After Radical \\ Resection. Dis Colon Rectum 2018;61:1273-80.
}

Submitted Jan 20, 2019. Accepted for publication Feb 13, 2019.

doi: 10.21037/cco.2019.02.01

View this article at: http://dx.doi.org/10.21037/cco.2019.02.01

It is a great honor to comment on the article entitled "Prognostic impact of hypochloremia in patients with stage I to III colorectal cancer after radical resection" by Qingguo $\mathrm{Li}$ and his colleagues in the Diseases of Colon and Rectum (1).

This retrospective study investigated the prognostic role of electrolyte disorders in patients with stage I to III colorectal cancer (CRC) who underwent radical surgical resection. The study included 5,089 such patients at a single institution from April 2007 to April 2014. The KaplanMeier method was employed to estimate the overall survival (OS) and disease-free survival (DFS) with and without propensity score (PS) matching. In the pre-matching analysis, patients with hypochloremia $(<102 \mathrm{mmol} / \mathrm{L})$ showed shorter OS (HR $=0.943 ; 95 \%$ CI, 0.908-0.980; $\mathrm{P}=0.003)$ and DFS (HR $=0.957 ; 95 \% \mathrm{CI}, 0.933-0.981$; $\mathrm{P}<0.001)$. The PS matching analysis performed on 770 patients in each group (low serum chloride $v s$. normal serum chloride) confirmed that hypochloremia was significantly associated with worse $\mathrm{OS}$ ( $\mathrm{HR}=0.646$; 95\% CI, 0.489$0.855 ; \mathrm{P}=0.002)$ and DFS (HR $=0.0 .782 ; 95 \% \mathrm{CI}, 0.647-$ 0.944; $\mathrm{P}=0.01)$. The authors concluded that hypochloremia diagnosed before treatment could independently predict the OS and DFS for patients with stage I to III CRC after radical resection.

Chloride is the most abundant anion in plasma and interstitial fluid, accounting for approximately one-third of plasma tonicity, and it affects acid-base changes $(2,3)$. Although chloride is an electrolyte that is mostly measured in daily practice, its role and metabolism have not been an area of focus and research when compared to other electrolytes, such as sodium, potassium, and calcium. Nonetheless, metabolic alkalemia is often observed in the perioperative course, and it has been widely known that it is primarily associated with electrolyte disturbances, such as hypokalemia and hypochloremia (4,5). An association has been previously reported between hypochloremia and mortality in critically ill patients (6-8). The authors speculated that hypochloremia was related to poor prognosis because (I) it could be a surrogate marker of malnutrition, and preoperative lower body mass index and older age may reflect nutritional deficiency in the patient before surgery (9); (II) it could be related to the status of preoperative chronic kidney disease (CKD) (10); and (III) some comorbidities such as liver disease (liver cirrhosis or hepatocellular carcinoma), diabetes mellitus, hypertension, and known heart failure had negative correlations with preoperative chloride levels.

However, the association between hypochloremia and increased mortality in patients with CRC has not been fully explored. In the study, the authors pointed out three elements to explain the association, including (I) stress, (II) hypochloremia reflecting the severity of CRC, and (III) abnormal expression of some ion channel proteins. At this time, as referred to in the article, there have been some reports about the abnormal expression of some ion channel proteins causing electrolyte disorders and leading to poor survival outcomes. However, we could not find any reports in PubMed that revealed the precise mechanism of hypochloremia leading to poor prognosis in CRC. Further basic and prospective clinical research is strongly expected.

Meanwhile, in addition to limitations that may have affected the results of the study, there are some points that we need to consider. First, because the original article mentioned that chemotherapy based on 5-fluorouracil 
was applied to patients with high risk stage II and III disease after radical resection, the absence of adjuvant chemotherapy with oxaliplatin base regimens may have led to poor prognosis, which could influence the results of the study. The authors did not mention the completion rate of treatment; this is another point of interest. Recently, Oh TK et al. reported that preoperative hypochloremia was related to an increased risk for postoperative acute renal dysfunction, and preoperative serum chloride level exhibited an independent relationship with mortality and morbidity after noncardiac surgery (11). Chemotherapy based on 5-fluorouracil is contraindicated, or reduced use is recommended for patients with kidney dysfunction; therefore, clarifying this point may lead to more persuasion. The influence of underlying CKD is another point of interest that was not mentioned in the article because previous studies have reported that hypochloremia in preoperative CKD causes poor prognosis for patients who are critically ill.

Second, the cutoff value of hypochloremia $(102 \mathrm{mmol} / \mathrm{L})$ is different from previous studies. Although there are no established cutoff values for hypo-, normo-, or hyperchloremia $(8,12,13)$, most studies use cutoff values of $98 \mathrm{mmol} / \mathrm{L}$ for hypochloremia and $110 \mathrm{mmol} / \mathrm{L}$ for hyperchloremia $(12,13)$. The authors showed a moundshaped histogram with the cutoff value of $102 \mathrm{mmol} / \mathrm{L}$ to define hypochloremia, which was derived from a large sample $(\mathrm{n}>800)$. However, a value of $102 \mathrm{mmol} /$ $\mathrm{L}$ is generally regarded as normochloremia. Oh $\mathrm{HJ}$ et al. reported that that the 28-day mortality rate in a hypochloremic group ( $<97 \mathrm{mmol} / \mathrm{L}$ ) was significantly decreased by $5.4 \%$ at $24 \mathrm{~h}$ with an increase of $1 \mathrm{mmol} /$ $\mathrm{L}$ in the chloride level after adjusting for age, sex, body mass index, systolic blood pressure, sequential organ failure assessment score, coronary arterial disease, serum albumin, and total $\mathrm{CO}_{2}$. However, there was no significant effect on 28-day mortality of 1 -mmol/L increase in the chloride level at $48 \mathrm{~h}$. In addition, in the normochloremic group $(98-110 \mathrm{mmol} / \mathrm{L})$, an increase of chloride level was not significantly associated with 28day mortality at any time (6). The effect of $1-\mathrm{mmol} / \mathrm{L}$ increase in the chloride concentration may be another point of interest in the original article for further study.

Third, as patients with stage I to III disease are grouped together in the study, subgroup analysis according to the $\mathrm{T}$ stage and $\mathrm{N}$ stage would be of interest. According to the 2016 Japanese Society for Cancer of the Colon and Rectum guidelines for the treatment of colorectal cancer (14), the recurrence rate after curative resection varies from $3.7 \%$ in stage I to $30.8 \%$ in stage III. The 5 -year survival rate is $91.6 \%$ in stage I, while it is $60.0 \%$ in stage IIIb.

Moreover, it is widely known that tumor location is another important factor that influences prognosis. It may be better to investigate the relationship with hypochloremia and these associated factors.

Discovering a simple and cost-effective predictable marker for patient prognosis is certainly a desirable goal. This article has focused on electrolyte disorders and prognosis in patients with stage I to III CRC. It may be the first article to emphasize serum chloride levels because we have not located any similar studies that have been previously published. Although the precise physiology and metabolic mechanism are unknown, the results of this study may be a milestone for further studies, leading to better outcomes in patients with CRC.

\section{Acknowledgments}

None.

\section{Footnote}

Conflicts of Interest: The authors have no conflicts of interest to declare.

\section{References}

1. Li Q, Dai, W, Jia H, et al. Prognostic Impact of Hypochloremia in Patients With Stage I to III Colorectal Cancer After Radical Resection. Dis Colon Rectum 2018;61:1273-80.

2. Berend K, van Hulsteijn LH, Gans RO. Chloride: the queen of electrolytes? Eur J Intern Med 2012;23:203-11.

3. Wolfe LA, Kemp JG, Heenan AP, et al. Acidbase regulation and control of ventilation in human pregnancy. Can J Physiol Pharmacol 1998;76:815-27.

4. Okusawa S, Aikawa N, Abe O. Postoperative metabolic alkalemia following general surgery: its incidence and possible etiology. Jpn J Surg 1989;19:312-8.

5. Galla JH. Metabolic Alkalosis. J Am Soc Nephrol 2000;11:369-75.

6. Oh HJ, Kim SJ, Kim YC, et al. An increased chloride level in hypochloremia is associated with decreased mortality in patients with severe sepsis or septic shock. Sci Rep 2017;7:15883.

7. Suetrong B, Pisitsak C, Boyd JH, et al. Hyperchloremia 
and moderate increase in serum chloride are associated with acute kidney injury in severe sepsis and septic shock patients. Crit Care 2016;20:315.

8. Tani M, Morimatsu H, Takatsu F, et al. The incidence and prognostic value of hypochloremia in critically ill patients. ScientificWorldJournal 2012;2012:474185.

9. Jacocks MA. Fluids. Electrolytes. Nutrition. In: General Surgery. Claudet RR, ed. New York, NY: Springer; 1993:1-10.

10. Jentsch TJ. Chloride transport in the kidney: lessons from human disease and knockout mice. J Am Soc Nephrol 2005;16:1549-61.

11. Oh TK, Do SH, Jeon YT, et al. Association of Preoperative Serum Chloride Levels With Mortality and Morbidity After Noncardiac Surgery: A Retrospective

Cite this article as: Tsutsui M, Yamamoto S. Impact of hypochloremia in resected colorectal cancer patients. Chin Clin Oncol 2019;8(Suppl 1):S16. doi: 10.21037/cco.2019.02.01
Cohort Study. Anesth Analg 2018. [Epub ahead of print].

12. Neyra JA, Canepa-Escaro F, Li X, et al. Acute Kidney Injury in Critical Illness Study Group. Association of Hyperchloremia With Hospital Mortality in Critically Ill Septic Patients. Crit Care Med 2015;43:1938-44.

13. Kimura S, Matumoto S, Muto N, et al. Association of serum chloride concentration with outcomes in postoperative critically ill patients: a retrospective observational study. J Intensive Care 2014;2:39.

14. Watanabe T, Muro K, Ajioka Y, et al. Japanese Society for Cancer of the Colon and Rectum. Japanese Society for Cancer of the Colon and Rectum (JSCCR) Guidelines 2016 for treatment of colorectal cancer. Int J Clin Oncol 2018;23:1-34. 